\title{
Are Men Who Pay for Sex Sexist? Masculinity and Client Attitudes Toward Gender Role Equality in Different Prostitution Markets
}

\author{
Barbara G. Brents \\ University of Nevada, Las Vegas, barb.brents@unlv.edu \\ Takashi Yamashita \\ University of Maryland Baltimore \\ Andrew L. Spivak \\ University of Nevada, Las Vegas, andrew.spivak@unlv.edu \\ Olesya Venger \\ University of Nevada, Las Vegas, olesya.venger@unlv.edu \\ Christina Parreira \\ University of Nevada, Las Vegas \\ Follow this and additional works at: https://digitalscholarship.unlv.edu/sociology_pubs \\ Part of the Criminology and Criminal Justice Commons, and the Feminist, Gender, and Sexuality \\ See nextpage for additional authors
}

\section{Repository Citation}

Brents, B. G., Yamashita, T., Spivak, A. L., Venger, O., Parreira, C., Lanti, A. (2020). Are Men Who Pay for Sex Sexist? Masculinity and Client Attitudes Toward Gender Role Equality in Different Prostitution Markets. Men and Masculinities 1-21. SAGE Publications.

http://dx.doi.org/10.1177/1097184X20901561

This Article is protected by copyright and/or related rights. It has been brought to you by Digital Scholarship@UNLV with permission from the rights-holder(s). You are free to use this Article in any way that is permitted by the copyright and related rights legislation that applies to your use. For other uses you need to obtain permission from the rights-holder(s) directly, unless additional rights are indicated by a Creative Commons license in the record and/ or on the work itself.

This Article has been accepted for inclusion in Sociology Faculty Publications by an authorized administrator of Digital Scholarship@UNLV. For more information, please contact digitalscholarship@unlv.edu. 


\section{Authors}

Barbara G. Brents, Takashi Yamashita, Andrew L. Spivak, Olesya Venger, Christina Parreira, and Alessandra Lanti 


\title{
Are Men Who Pay for Sex \\ Sexist? Masculinity and \\ Client Attitudes toward \\ Gender Role Equality in \\ Different Prostitution \\ Markets
}

@The Author(s) 2020

Article reuse guidelines:

sagepub.com/journals-permissions

DOI:10.1177/1097184X20901561

journals.sagepub.com/home/jmm

\author{
Barbara G. Brents', Takashi Yamashita ${ }^{2}$, \\ Andrew L. Spivak', Olesya Venger', \\ Christina Parreira', and Alessandra Lanti'
}

\begin{abstract}
Prostitution clients' attitudes toward gender equality are important indicators of how masculinity relates to the demand for commercial sexual services. Research on male client misogyny has been inconclusive, and few studies compare men in different markets. Using an online survey of 519 clients of sexual services, we examine whether male client attitudes toward gender role equality are related to the main methods customers used to access prostitution services (i.e., through print or online media vs. in-person contact). We found no differences among men in these markets in attitudes toward gender role equality in the workplace and home. This is in a context where all clients had more egalitarian attitudes toward women's roles than the U.S. male population in the General Social Survey (GSS). However, clients in in- person markets were less supportive of affirmative action than in online markets in a context where all clients were less supportive compared to the national average. These findings point to need to rethink how masculinity and gender role attitudes affect patterns of male demand for paid sex.
\end{abstract}

\section{Keywords}

criminology, deviance, gender equality, hegemonic masculinity, sexualities, united states, feminism, prostitution, prostitution demand, prostitution clients.

I Department of Sociology, University of Nevada, Las Vegas, NV, USA

2 Department of Sociology, Anthropology, and Health Administration and Policy, University of Maryland Baltimore County, Baltimore, MD, USA

Corresponding Author:

Barbara G. Brents, Department of Sociology, University of Nevada, Las Vegas Maryland Parkway, Box 455033. Las Vegas, NV 89I54-5033, USA. Email: barb.brents@unlv.edu 


\section{Are Men Who Pay for Sex Sexist? Masculinity and Client Attitudes toward Gender Role Equality in Different Prostitution Markets}

Anti-prostitution feminists have long argued that prostitution is produced by and produces a cultural ideal of masculinity based on dominance and control of women (Barry, 1995; Dworkin, 1993). Not all individuals who pay for sex are men, men and transgender individuals provide services (Minichiello \& Scott, 2014; Weitzer, 2009), and studies find real diversity among male clients in different markets (Stewart Cunningham et al., 2018; Della Giusta, Di Tommaso, Shima, \& Strom, 2009; Monto, 2010; Monto \& Milrod, 2014; Sanders, 2008b). Nonetheless, because mostly men buy and women sell, proponents of criminalizing clients, for example "End Demand" policies or the "Nordic Model," are motivated at least in part, by arguments that "Gender equality will remain unattainable so long as men buy, sell, and exploit women" (Ekberg, 2005; Skilbrei, 2012).

Men's attitudes about gender equality are one important piece of this debate. These attitudes are important indicators of how masculinity relates to the demand for commercial sexual services. Relatively little research in sexual commerce has looked at clients' attitudes about women's roles directly and even less has looked for differences among client groups. Most research examines violent or aggressive attitudes, finding no consistent evidence that clients accept rape myths, score high on entitlement, control or similar scales more than other men (Busch, Bell, Hotaling, \& Monto, 2002; Della Giusta et al., 2009; Farley, Golding, Matthews, Malamuth, \& Jarrett, 2017; Joseph \& Black, 2012; Monto \& Hotaling, 2001; Monto $\&$ Milrod, 2014). Others argue that prostitution may be fed by attitudes more typical of other consumers in a service economy -- a neoliberal "market morality," "bounded authenticity" or consumer masculinity connected to individual freedom, contract-based fulfillments of needs, sexual liberalism and tolerance that is connected to support for gender equality (Bernstein, 2007; Brents, 2016; Brents, Jackson, \& Hausbeck, 2010; Joseph \& Black, 2012; Milrod \& Weitzer, 2012; Peng, 2007; Pettinger, 2013; Prasad, 1999; Sanders, 2008a, 2008b).

How do gender role attitudes relate to the market for paid sex? Are more sexist men likely to participate in the more vulnerable markets? Is masculinity in sex markets inevitably sexist? Or might support for equality in women's roles be consistent with a consumer masculinity that is part of the demand for sexual consumption? Exploring client attitudes towards gender-role equality can better explain the connection between masculinity, gender inequality and the demand for paid sex. As Birch, et al., point out, researching gender attitudes in male clients can provide new insights into theorizing masculinities (Birch, Baldry, \& Hartley, 2017).

The current study uses survey data to examine the link between client attitudes toward gender role equality and the methods clients use to seek service providers. We first contextualize our sample by comparing male clients' attitudes toward gender equality with a nationally representative sample of males in the U.S. We then compare attitudes across different client groups. We use a unique data source, an online survey of 519 men that asked about patterns in accessing sexual services in several markets. Preferred markets were measured by whether customers indicated that they contacted providers more frequently inperson (e.g. street, bar or hotel) or through mediated means - electronic and print media. Our survey was conducted before 2018 legislation in the U.S. closed many online venues, restricting the visibility and accessibility of the online environment. While bar and hotel rendezvous are typically seen as safer than street markets, we felt that service providers who were unable to pre-screen clients were significantly more vulnerable compared to online and print clients who could interact prior to arranging services. Our survey borrowed questions from the General Social Survey (GSS) that are commonly used to measure attitudes about gender equality across four dimensions: (i) working mothers; (ii) women in politics; (iii) traditional gender roles in the family; and (iv) affirmative action for women in the workplace. The research question that underlies the study: Are male client gender egalitarian attitudes 
associated with the methods they used to contact sex service providers (online/print media vs. face to face)?

We found no difference between markets in attitudes toward women's equality in the workplace and in the home. Indeed, our descriptive data found clients in all markets are significantly more likely to have positive attitudes toward gender role equality than men in the GSS. Our findings overall contribute to research showing that negative attitudes toward women is not central to the demand for paid sex (Joseph \& Black, 2012; Milrod \& Monto, 2012; Peng, 2007; Sanders, 2008a) and that consumer, flexible, or inclusive masculinities that do not rest entirely on othering or devaluing women are key to understanding sexual consumption. Paying for sex should be examined in the context of other consumer and leisure services.

\section{Client attitudes and gender inequality}

Traditional gender roles are important in the sex industry. Men report paying for sexual services because their partners are unable to fulfill their sexual needs or they want emotional care or a girlfriend experience (Milrod \& Weitzer, 2012; Monto, 2010; Sanders, 2008a, 2008b) suggesting that clients may hold traditional attitudes about women's roles at home or as caregivers. But do these gendered motives inescapably rest on devaluing women's roles, power or abilities?

The notion that prostitution legitimates gender inequality rests in large part on the concept of hegemonic masculinity -- an aspirational and relational configuration of discourses, attitudes and behaviors that legitimizes men's dominance over women through bifurcating gender, positioning masculinity against the feminine and discrediting and devaluing women or women's roles (Connell \& Messerschmidt, 2005). Research exploring masculinities among men who pay for sex finds that some groups indeed construct their sense of manhood against women's roles and power. For example, some arrested clients evidence a "fragile masculinity" (feeling unattractive, insecure and rejected in relation to women) that makes them more likely to hold negative and aggressive attitudes toward women (Joseph \& Black, 2012). Or they assert masculinity characterized by beliefs about women's inferiority and lack of abilities (Besbris, 2016; Shumka, Strega, \& Hallgrimsdottir, 2017). Huyasamen and Boonzeler suggest that the online clients they interviewed prefer sex without commitment because they see women as devious and manipulative, striving for hegemonic male sexuality in exaggerated, aggressive, hostile, or hypermasculine ways (Huysamen \& Boonzaier, 2015). In these studies, the struggle to attain masculinity among clients is a gender zero-sum game where a belief in gender equality does not coexist with the masculinity involved in paying for sex.

On the other hand, research on some sex buyers finds that gendering isn't necessarily based on attitudes opposed to female power. Sanders finds that regulars, men who return to the same providers for services, talk about escaping from the dominant roles they often play in their other worlds, and it was not a discourse of entitlement (Sanders, 2008b). Studies of clients in indoor markets find similar patterns, that clients view paying for sex more as one would other consumer services, using their consumer power to meet physical, sexual, emotional or social needs (Bernstein, 2007; Joseph \& Black, 2012; Milrod \& Monto, 2016; Milrod \& Weitzer, 2012; Peng, 2007; Pettinger, 2013; Sanders, 2008a, 2008b). Valuing women's abilities as "professionals" seems to characterize clients in online markets as much as a desire for feminine services (Pettinger, 2011). Others find clients are motivated by clear rules in the economic exchange; paying for sexual services lacks the ambiguity, status-dependence, and potential hypocrisy of romantic sex (Prasad, 1999). The clarity of norms in an economic exchange might result in less misogyny toward service providers or be less threatening to masculinity compared to ambiguous norms surrounding romantic sex. Indeed, the same study that found evidence for a link between fragile masculinity and potential violence also found evidence for a "consumer masculinity" among these arrested clients (those who treat sex as a consumer good for diversion, experimentation, and sexual release) that was not linked to violent or misogynistic attitudes (Joseph \& Black, 2012). 
Research looking at the role of gender in commercial sex often links client motivations to traditional masculine traits such as being unemotional, hyper-sexual, risk seeking, aggressive, or overtly heterosexual. Recent theorizing on masculinities has found evidence for flexible, inclusive or hybrid masculinities that incorporate rather than wholly reject "Others" into the gender identity process, and are less violent, more emotional and more gender equitable (Anderson \& McCormack, 2018; Birch et al., 2017; Bridges \& Pascoe, 2014). Studies of how clients seek intimacy or escape from masculine roles (Z. Jones \& Hannem, 2018; Milrod \& Weitzer, 2012; Sanders, 2008b) points to a more complex expression of masculinity in commercial sex in some situations. Birch argues that most clients do not exhibit hypermasculinity, and that clients, far from being unemotional, attend to their emotional needs by seeking providers (Birch et al., 2017). Lahav Raz's studied how clients' in online forums talk about their exploits in seeking street workers and found that they performed power and validated their masculinity more in relation to other men than to women (Lahav-Raz, 2019a). While client attitudes toward gender equality are but one component of masculine repertoires, they are key to understanding how certain groups of men may define themselves in relation to women.

Support for gender egalitarian attitudes is increasing in the U.S. (Bolzendahl \& Myers, 2004; Kane \& Whipkey, 2009). Others note that we are in the midst of a "stalled revolution" -. beliefs about women's necessary care giving roles in the interpersonal realm persist alongside egalitarian attitudes about women in the workplace (Cotter, Hermsen, \& Vanneman, 2011; England, 2010; Scarborough, Sin, \& Risman, 2018). Others find support for gender equality but variation in support for affirmative action (Levtov, Barker, Contreras-Urbina, Heilman, \& Verma, 2014). Knight and Brinton find that gender-role attitudes are split across the dimensions of egalitarianism, essentialism (a belief that men and women have fundamentally different traits), and a third individual choice belief set supporting gender equality at work but not that men and women must have equal work roles, reflecting an individualistic belief in free choice (Knight \& Brinton, 2017). These findings highlight "how multidimensional attitudes around gender are, and how other beliefs and values based on local realities (e.g., about the role of government and free markets, or about the fair and consistent application of the law) interact with gender ideologies" (Levtov et al., 2014, p. 491).

\section{Diversity in prostitution markets}

Where clients contact providers matter a great deal. Street sex markets draw more vulnerable sellers and buyers with fewer financial and social resources, and both parties, but especially the workers, are likely to encounter violence in the environment by police or criminals (Connelly, Kamerāde, \& Sanders; Deering et al., 2014; Weitzer, 2009). On the other hand, print ads, and more recently, digital communications provide distance in time and space allowing both buyer and seller to gather more information, be more selective and screen out dangerous or undesireable clients and situations (Armstrong, 2014; Campbell, Sanders, Scoular, Pitcher, \& Cunningham, 2018; Scott Cunningham \& Kendall, 2011; Monto \& Milrod, 2014; Nelson, Hausbeck Korgan, Izzo, \& Bessen, 2019; Sanders, 2008a, 2008b). Even workers in fixed locations, such as brothels or parlors, can use the internet or similar mechanisms to arrange appointments and assess clients more than can workers on the street or even a bar or hotel (Brents \& Hausbeck, 2005; Stewart Cunningham et al., 2018). While the 2018 shuttering of many online sites put providers and clients with fewer resources back on the streets, there is evidence that less visible online platforms continue as an important part of commercial sex markets globally (Stewart Cunningham et al., 2018).

Studies of client interactions in online review sites finds that buyers regulate themselves, standardizing conduct, socializing novices and placing respect or connection with workers at forefront (Horswill \& Weitzer, 2018; Milrod \& Monto, 2012; Milrod \& Weitzer, 2012). Monto and Milrod compared data from hobbyists in an online review site with a data set of arrested customers, who tend to be more ethnically diverse and inexperienced, and found differences in attitudes, motivations and experiences (Monto \& Milrod, 2014). Whether clients with certain 
attitudes choose certain markets or whether the market affects their attitudes, these findings highlight the need to examine differences among clients in different markets.

\section{Methods}

Due to difficulty accessing representative samples of sex buyers for statistically significant comparisons, there are very few large-scale studies and even fewer with the ability to differentiate among clients. Data for this paper is based on a unique online survey of clients of sexual services collected between 2015 and 2017. ${ }^{1}$ Research team members enlisted the help of individuals in the sex work community to help recruit consumers of adult services and spread the survey URL. We promoted the survey on social media, online, print and radio news, email groups, online forums and other online sources encouraging circulation to potential participants, and posted the URL of the survey on the first author's faculty web-page for ease of access. Several sex worker bloggers posted information to their clients. We also recruited clients of Nevada's legal brothels, recognizing that many also pay for illegal services, although we excluded respondents who only used legal brothels from this study. We posted survey announcements in an online forum for legal brothel clients (CyberWhore Mongers Club), and on one large legal brothel webpage. In addition, organizers posted an email announcement to individuals registering for the CyberWhore Mongers Club annual meeting. While consumers of sexual services can include a wide variety of services, we eliminated all surveys of individuals who indicated that they had not "paid for sex."

We realized our methods would likely bias toward subjects who access sexual services online. Our questions, however, also asked about the range of ways in which respondents accessed sexual services, and indeed, we found a significant number of individuals who accessed sellers in various ways, including mostly through in-person encounters.

We obtained data on American adults aged 18 and older from the 2014 General Social Survey to estimate the nationally representative figures to compare to the study respondents in our customer survey (Smith, Marsden, Hout, \& Kim, 1976-2016). Our data was collected between June 2015 and June 2017, however because more than half of our subjects responded during 2015 and relatively few during 2017, we decided that the 2014 GSS data were the most comparable national data. The information available in the GSS includes sociodemographic characteristics, attitudes toward society, and politics in general. Given that the survey respondents in our survey were predominantly men (approximately 94\%), we used only male respondents both from our customer survey and the GSS data. After excluding women and cases with missing values in key variables (see below), the final sample sizes for our buyer survey was 519 . The sample from the GSS was 1,141 .

\section{Dependent Variable}

Clients were classified into two groups - those using mediated online/print or in-person contact. Respondents were asked, "About how many times have you ever paid for sex, or attempted to make arrangements to pay for sex, under each of the following circumstances? (It's okay if circumstances overlap)." Choices included contacting someone in outdoor public place, indoor public place (such as a bar, casino, or strip club), indoor private place (such as a massage parlor or sex club, excluding the legal brothels), through printed materials (flyers, cards, phone books) or online sources. Each item was assessed 7-point Likert-like scale [1-7: (1) never; (2) 1-2 times; (3) 3-4 times; (4) 5-6 times; (5) 7-8 times; (6) 9-10 times; (7) more than 10 times]. For the media-group and in-person group, the average frequencies of two and three items were computed, respectively. Among the media group, average frequencies for the media and in-person contact were 3.86 and 1.97 (about 55\% of them never used the in-person contact). Among the in-person group, average frequencies for the media and in-person contact were 1.89 (about $45 \%$ of them never used the media contact) and 3.29. Although some used

\footnotetext{
${ }^{1}$ UNLV Institutional Review Board, Consumption and Adult Entertainment Research Project, protocol number 1102-3717.
} 
both nearly equally, respondents were classified into a group based on the greater average frequency. As seen in the mean frequencies, the ways two groups access to the sex service are appreciably different. We excluded those who visited legal brothels because legal prostitution is rare in the US, little is known about those buyers, and there were some distinctive characteristics (e.g., attitudes, socioeconomic status) among brothel buyers. Due to the small sample size from the non-systematic sampling we were uncertain about the comparability to illegal clients.

\section{Independent Variables}

We adopted four questions on attitudes toward gender equality that have been asked regularly in the GSS and frequently are used to assess gender role attitudes (Cotter et al., 2011; England, 2010; Kane \& Whipkey, 2009; Knight \& Brinton, 2017; Scarborough et al., 2018). For this study, evidence for positive attitudes toward gender equality was operationalized as holding negative attitudes toward working women's ability to care for children and special efforts to promote qualified women and holding more positive attitudes toward men being more suited for politics and women not working outside the home. Specifically, the survey items we used were, "A working mother can establish just as warm and secure a relationship with her children as a mother who does not work," "Because of past discrimination, employers should make special efforts to hire and promote qualified women," "Most men are better suited emotionally for politics than are most women," and "It is much better for everyone involved if the man is the achiever outside the home and the woman takes care of the home and family." The responses were originally recorded in 4-point Likert Scale (strongly agree, agree, disagree, strongly disagree) but were dichotomized to "Agree" and "Disagree" due to the skewed distributions and insufficient sample sizes (less than 5\% of the total sample) in several categories. The same survey items were used from the GSS data and the response categories were made comparable (i.e., dichotomized) to the present study. One of the GSS survey items, "Because of past discrimination, employers should make special efforts to hire and promote qualified women," had an additional response category, "Neither agree or disagree," and this response category was removed from the analysis to make it consistent with other survey items. Interpretation of findings about this particular survey item requires caution due to this difference in response categories. We choose to analyze items separately rather than combine them because of the size of the sample and its lack of representativeness. We were also interested in seeing possible differences among items that deal with attitudes about familial and workplace roles.

\section{Covariates}

The covariates were selected considering the theoretical relevance of the key variables and parsimony in the statistical analysis. Age at the time of the survey was recorded in years. Race and ethnicity were dichotomized to non-Hispanic whites and others (e.g., blacks, Hispanics, Asians) because the vast majority (over $86 \%$ ) of the respondents were white. Marital status and educational attainment were dichotomous variables (married vs. not married; college or higher degree vs. less than college, respectively). Household income was assessed with the 11 levels, roughly by $\$ 20,000$ [(1) Under $\$ 20,000$, (2) $\$ 20,000$ to $\$ 39,999 \ldots$ and (11) over $\$ 200,000]$. The same information was extracted from the GSS data, except for the household income due to the incomparable response categories.

\section{Analytic Strategies}

Two sets of analyses were sequentially conducted. First, the descriptive summaries of the survey respondents were compared to the national average. We incorporated the sampling weights into the estimation of nationally representative figures. The PROC SURVEYFREQ and SURVEYMEANS commands were used in SAS version 9.4 (Copyright (C) 2013, SAS 
Institute Inc.). The bivariate significance tests (i.e., t-test or chi-square test) were used to compare the data in the present study to the national average.

Second, a series of binary logistic regressions were conducted to address the main research question (Hosmer, Lemeshow, \& Sturdivant, 2013). The PROC LOGISTIC command in SAS 9.4 was used to model methods of accessing sexual services as a function of gender attitudes. For each gender attitude item, an unconditional model was evaluated. Only if a statistically significant association was identified was a fully conditional model constructed. The model quality was assessed using the Akaike Information Criterion (AIC) and the area under the Receiver Operating Characteristics (ROC) curve (Hosmer et al., 2013). AIC indicates how well the model fits to the data, and the area under the ROC curve indicates the sensitivity (i.e., correctly detect any statistically significant effect) and specificity (i.e., correctly reject any statistically non-significant effect). A lower AIC and a greater area under the ROC curve indicate better model fit and predictive accuracy. Statistical significance was based on an alpha value of 0.05 .

\section{Results}

Table 1 presents the descriptive summaries (i.e., mean and standard deviation, or percentage for the study sample; weighted mean and standard error, or weighted percentages for the GSS sample) of client groups as well as the bivariate test results and compares them with a national sample of men taken from the 2014 GSS. The test statistics are presented in Table 1 . The results are summarized below.

Among the client survey participants $(n=519)$, the majority, 354 (about 68\%) of them were classified in the media group; that is, they accessed sexual services primarily either online or through print media. The average age of the client survey respondents $(47.84 ; p>$ $0.05)$ was similar to the national average ( 47.6 years old). The average age of the media (47.35; $p>0.05)$ and in-person $(48.90 ; p>0.05)$ groups were also comparable to the national average. Survey respondents were less likely to be married $(34.17 \% ; p<0.05)$ compared to the national average (55.04\%). This finding was consistent for the media (34.84\%) and in-person $(38.79 \%)$ groups. There was no statistically significant difference in the educational attainment between any of the groups $(32.73 \%-34.84 \%)$ and the national average $(30.81 \%)$.

Surprisingly, gender role attitudes of all surveyed clients in all groups were consistently more positive than the national average (all $p<0.05$ ), except for the question on special efforts to promote and hire more women. Significantly fewer survey respondents $(48.06 \% ; p<0.05)$ supported these special efforts than the national average (69.54\%). However, interpretations of the difference in the special efforts question between our sample and the GSS require caution because GSS data contained an additional response category "Neither agree or disagree" that was removed from the analysis to make it consistent with other client survey items.

Table 2 presents results from the binary logistic regressions. The difference in men who used media vs. in-person was not significantly associated with attitudes toward the working mother (Model 1), women in politics (Model 2), and traditional gendered family roles (Model 3 ). Therefore, we did not include the control variables because the baseline model was not significant, and no further analysis was conducted for these three attitudinal items.

There was a statistically significant association between the media vs. in-person markets and the attitude toward special efforts to promote and hire more women at work $(b=0.73, \mathrm{SE}$ $=0.21, p<0.05)$. Specifically, clients with positive attitudes toward special efforts to promote women had 2.08 times greater odds of using media to access sexual services, compared to those with negative attitudes. Based on the AIC and area under the ROC curve of the final model (Model $4 \mathrm{~b}$ in Table 2), the quality of the final model was better than the unconditional model (Model 4). However, the predictive accuracy (area under the ROC curve $=0.64$ ) is slightly lower than the suggested cut-off point of 0.70 (Swets, 1988), although greater than the unconditional model (0.56). Taken together, our overall evaluation of the final model is adequate given the lack of previous empirical evidence on client attitudes toward affirmative action in these market classifications. However, future research with other information (e.g., 
more detailed client behaviors/classifications) is needed to improve the predictive accuracy of the model.

Age, race/ethnicity, and household income were significantly associated with methods of contacting service providers. Older clients were less likely to use media than in-person contact. Consistent with most research, non-Hispanic whites were more likely to use media than inperson contact. Finally, those with greater household income were more likely to use media than in-person contact. These findings of the covariates suggest that there are differences between individuals in the methods they use to access sexual services and gender attitudes.

\section{Discussion}

The most surprising finding in the descriptive data was that men in all markets were significantly more likely to support gender equality for women's roles in the home, work and politics than the general population of males. This contradicts the view that men who pay for sex devalue women's power, abilities, and roles. While our sample was less ethnically diverse and fewer were married than in the general population, these differences would not seem to explain why clients in our sample were more supportive of gender role equality.

Do male clients' attitudes toward gender equality relate to the markets in which they mainly participated? We found few differences; egalitarian attitudes were similar across markets in most questions. The absence of differences among client markets in three of the four questions - women being emotionally suited for politics, women working outside the home, and working women's ability to take care of children - is important. That clients' generally positive attitudes were not associated with different markets means that these client attitudes likely play no central role in providers' greater experiences of violence or exploitation in in-person markets. Numerous studies point to a variety of contextual factors that explain violence or negative experiences among street workers, including legal and policing policies and practices, economic conditions, stigma, and other structural relations of power (Connelly et al.; Deering et al., 2014; Monto \& Milrod, 2019). Many factors explain sex workers' experiences in different markets, but attitudes towards gender role equality does not seem to be one of them, although a wider range of gender attitudes, masculine repertoires and structural factors should be examined.

Attitudes on affirmative action did matter in the descriptive statistics. Men using media markets were more supportive of special efforts to promote or hire qualified women in the workplace than men using in-person markets. This is in a context where clients in both markets were less likely to support special efforts than the population as a whole. While questions on gender-related affirmative action are frequently used to measure support for equality in the workplace, sexism in gender-role attitudes does not play a big role in predicting attitudes toward gender-based affirmative action (Harrison, Kravitz, Mayer, Leslie, \& Lev-Arey, 2006; Kane \& Whipkey, 2009). One cross cultural study found male attitudes toward gender based affirmative action are generally lower among some otherwise egalitarian men (Levtov et al., 2014). Questions on gender based affirmative action are found to be less related to gender and more to issues such as race-related affirmative action, opinions about government involvement with market forces, meritocracy, free choice, or class based perceptions about one's own workplace chances (Kane \& Whipkey, 2009; Morgenroth \& Ryan, 2018). But we definitely need more research.

Based on the results from the regression analysis, we found that in-person clients, who were more likely non-white, single and lower income, were more likely to be against special efforts. This is curious as other findings suggest that these more marginalized groups more likely support gender based affirmative action (Harrison et al., 2006; Kane \& Whipkey, 2009). Yet, in our study, this finding is robust -- we controlled all covariates in the model and the special effort variable was still significant. It could be that these individuals were more akin to flexible egalitarians who tend to support individual choice in roles, and affirmative action was seen as antithetical to free choice (Knight \& Brinton, 2017). In terms of the effect size, the estimated odds ratio indicates the relative contribution of affirmative action attitudes to market preference after adjusting for covariates. It is possible that that clients who prefer street 
markets are more threatened by affirmative action policies. However, given the lack of empirical evidence on the same topic, the magnitude of such effect should be further examined in future research when other comparable data become available. This issue is certainly worthy of further study, especially using different measures of the various dimensions of egalitarianism.

\section{Study Limitations}

Our sample is certainly not representative of all men who pay for sex. As long as they remain an underground and stigmatized population, it is unlikely there will ever be a representative sample of clients. Regular and frequent clients are more likely to access review sites, online blogs, or social media than casual or one-time consumers (Milrod \& Monto, 2012; Sanders, 2008b). Our online recruitment process likely missed the full range of individuals who use face to face methods and who do not regularly use the internet (Shumka et al., 2017).

Online recruitment methods also access mostly white clients (Shumka et al., 2017), which was the case for our sample. Our recruitment strategy began with subjects in a particular geographic area, ie. the Nevada's brothels, and this population is fairly racially homogenous (Brents et al., 2010), although we excluded brothel only clients. Given the importance of exploring racial and ethnic diversity within prostitution markets (A. Jones, 2015), future research should pay attention to the demographic characteristics within online and face to face prostitution markets.

Also, the classification method of clients (media vs. in-person) was one of many possible approaches one could take to differentiating markets (Stewart Cunningham et al., 2018; A. Jones, 2015). Many respondents used both mediated online/print and in-person markets. Our classification was somewhat simplistic, the available sample size was insufficient for more indepth analysis. Future research should explore more detailed client-type classifications referring to our study for baseline findings.

In addition, due to low cell sizes, our in-person group included those who initially made contact in a bar or hotel, a space that is typically classed as an indoor venue and seen as somewhat safer than the street. We opted for a distinction based on the ability of client and provider to screen each other, a distinction that greatly affects safety in markets and the amount of third-party control. However, it is also the case that hotel and bar buyers are more similar to other indoor buyers in some respects. Future research should be able to understand if face to face initial contact in a bar or hotel is different than on the street.

Also, our study only focused on the examination of associations, and results should not be interpreted as implying causality. Although our sample was sufficient to address the research questions, the causal relationship should be investigated using longitudinal data in future research. Finally, our sample of GSS men includes the $13.9 \%$ who report that they have paid for sex in their lifetimes (Monto \& Milrod, 2014). Future research should examine the subpopulations (e.g., individuals who have paid vs. those who never paid for sex).

\section{Conclusions}

Male client attitudes about gender equality are one piece of the puzzle of how masculinities relate to the demand for paid sex. Our study's descriptive comparison found that clients are more positive toward gender equality than the population of men, and that most attitudes were not related to preferences for different markets for commercial sex. This supports other research that the demand for commercial sex is not uniformly motivated by negative attitudes toward gender role equality, and thus demand may not be centrally driven by a masculinity built on devaluing women's place in society.

Client support for equality in women's roles is consistent with attitude research showing that enjoyment of sexual pleasure and even support for extra-marital sex are in line with support for gender equality and support for prostitution in neoliberal regimes (Stack, Adamczyk, \& Cao, 2010). Trends like the increasing demand for and value of the girlfriend experience, companionship or mutual enjoyment, normative pressures to show respect for women in online review sites, and the existence of consumer masculinities in purchasing 
sexual services, collectively might be contributing to more egalitarian attitudes toward women in all markets among the average client. We need more research in various markets.

Contemporary masculinity theorizing finds that masculine performances are enacted in relation to other men and to marginalized masculinities as well as in relation to women. While preliminary, our findings suggest that the demand for sexual services coexists with less oppressive and more gender egalitarian forms of masculinities -- flexible, inclusive or hybrid masculinities that are not entirely dependent upon the negation or exclusion of women (and gay men) in certain leisure spaces (Anderson \& McCormack, 2018; Birch et al., 2017; Bridges \& Pascoe, 2014; Crowhurst \& Eldridge, 2018; Hearn et al., 2012).

In addition, the demand for sexual services doesn't just reflect attitudes toward women. The apparent inconsistency in answers to questions on affirmative action actually aligns with neoliberal cultural values such as individual autonomy, class and color-blind attitudes that reject these differences as determinant of life chances and affirm the superiority of contractbased exchange (Harvey, 2007). Clients in our study thus may care more about free choice, free markets, the role of government, fair and consistent application of the law (Knight \& Brinton, 2017; Levtov et al., 2014) than about gender inequality (Harrison et al., 2006; Kane \& Whipkey, 2009). Thus, these kinds of free choice market moralities (Brents, 2016; Pettinger, 2013; Prasad, 1999) may be as important in framing attitudes toward commercial sex in western culture as sex and gender role attitudes. This market morality includes values centered on "autonomy, democratic equality, and unambiguous and non-discretionary fulfillment of obligations" (Prasad, 1999, p. 185), whether it be called "consumer masculinities" (Joseph \& Black, 2012), "bounded authenticity" (Bernstein, 2007), or "deserving consumers" (Pettinger, 2013) to justify the superiority of prostitution over the gift exchange inherent in relational sex (Brents \& Hausbeck, 2007; Milrod \& Weitzer, 2012). Exploring this market morality and its relation to sexual consumption is a question certainly worth pursuing in future research.

As this and other research indicates, efforts to promote gender equality should tap into this support for gender equality among clients (Jewkes, Flood, \& Lang, 2015; Levtov et al., 2014). Cross cultural studies find that for the most part, men's equitable attitudes were associated with equitable practices (Levtov et al., 2014). Misogyny does exist in the sex industry, but given the ability of clients to collectively create market norms online (Lahav-Raz, 2019b), policies criminalizing clients or closing online forums to correct gender injustices may unwittingly cut off avenues for positive socialization among clients with gender egalitarian attitudes (Armstrong, 2014; Horswill \& Weitzer, 2018). Understanding the complexities of client attitudes toward women, and especially how these may change with different market preferences, can add important insights into how consumer culture interacts with what it is to be a man in the twenty-first century (Birch et al., 2017).

\section{Declaration of Conflicting Interests}

The author(s) declared no potential conflicts of interest with respect to the research, authorship, and/or publication of this article.

\section{Funding}

The author(s) received no financial support for the research, authorship, and/or publication of this article.

\section{Notes}

1. UNLV Institutional Review Board, Consumption and Adult Entertainment Research Project, protocol number 1102-3717.

\section{References}


Anderson, E., \& McCormack, M. (2018). Inclusive masculinity theory: Overview, reflection and refinement. Journal of Gender Studies, 27(5), 547-561.

Armstrong, L. (2014). Screening clients in a decriminalised street-based sex industry: Insights into the experiences of new zealand sex workers. Australian \& New Zealand Journal of Criminology, 47(2), 207-222.

Barry, K. (1995). The prostitution of sexuality. New York: New York University Press.

Bernstein, E. (2007). Temporarily yours: Intimacy, authenticity and the commerce of sex. Chicago: University of Chicago Press.

Besbris, M. (2016). Revanchist masculinity: Gender attitudes in sex work management. The Sociological Quarterly, 57(4), 711-732.

Birch, P., Baldry, E., \& Hartley, V. H. (2017). Procuring sexual services: Evidencing masculinity diversity and difference through sex work research. Sexuality \& culture, 21(4), 1106-1119.

Bolzendahl, C. I., \& Myers, D. J. (2004). Feminist attitudes and support for gender equality: Opinion change in women and men, 1974-1998. Social Forces, 83(2), 759-789.

Brents, B. G. (2016). Neoliberalism's market morality and heteroflexibility: Protectionist and free market discourses in debates for legal prostitution. Sexuality Research and Social Policy, 13(4), 402-416.

Brents, B. G., \& Hausbeck, K. (2005). Violence and legalized brothel prostitution in nevada: Examining safety, risk and prostitution policy. Journal of interpersonal violence, 20(3), 270-295.

Brents, B. G., \& Hausbeck, K. (2007). Marketing sex: U.S. Legal brothels and late capitalist consumption. Sexualities, 10(4), 425-439.

Brents, B. G., Jackson, C., \& Hausbeck, K. (2010). The state of sex: Tourism, sex and sin in the new american heartland. New York: Routledge.

Bridges, T., \& Pascoe, C. J. (2014). Hybrid masculinities: New directions in the sociology of men and masculinities. Sociology Compass, 8(3), 246-258.

Busch, N. B., Bell, H., Hotaling, N., \& Monto, M. A. (2002). Male customers of prostituted women. Violence Against Women, 8(9), 1093.

Campbell, R., Sanders, T., Scoular, J., Pitcher, J., \& Cunningham, S. (2018). Risking safety and rights: Online sex work, crimes and 'blended safety repertoires'. The British journal of sociology.

Connell, R. W., \& Messerschmidt, J. W. (2005). Hegemonic masculinity: Rethinking the concept. Gender \& Society, 19(6), 829-859.

Connelly, L., Kamerāde, D., \& Sanders, T. (2018). Violent and nonviolent crimes against sex workers: The influence of the sex market on reporting practices in the united kingdom. Journal of interpersonal violence, $0(0), 0886260518780782$.

Cotter, D., Hermsen, J. M., \& Vanneman, R. (2011). The end of the gender revolution? Gender role attitudes from 1977 to 2008. American Journal of Sociology, 117(1), 259-289.

Crowhurst, I., \& Eldridge, A. (2018). “A cathartic moment in a man's life” homosociality and gendered fun on the puttan tour. Men \& Masculinities, $1097184 X 18766578$.

Cunningham, S., \& Kendall, T. D. (2011). Prostitution 2.0: The changing face of sex work. Journal of Urban Economics, 69(3), 273-287.

Cunningham, S., Sanders, T., Scoular, J., Campbell, R., Pitcher, J., Hill, K., Valentine-Chase, M., Melissa, C., Aydin, Y., \& Hamer, R. (2018). Behind the screen: Commercial sex, digital spaces and working online. Technology in Society, 53(May), 47-54.

Deering, K. N., Amin, A., Shoveller, J., Nesbitt, A., Garcia-Moreno, C., Duff, P., Argento, E., \& Shannon, K. (2014). A systematic review of the correlates of violence against sex workers. American Journal of Public Health, 104(5), e42-e54.

Della Giusta, M., Di Tommaso, M. L., Shima, I., \& Strom, S. (2009). What money buys:

Clients of street sex workers in the us. Applied Economics, 41, 2261-2277.

Dworkin, A. (1993). Prostitution and male supremacy. Michigan Journal of Gender \& Law, 1, 1.

Ekberg, G. (2005). Prostitution and trafficking in human beings: Fact sheet. In E. a. C. 
Ministry of Industry (Ed.), (Vol. Article no. N5029). Stockholm: Ministry of Industry, Employment and Communications, Division for Gender Equality.

England, P. (2010). The gender revolution: Uneven and stalled. Gender \& Society, 24(2), 149166.

Farley, M., Golding, J. M., Matthews, E. S., Malamuth, N. M., \& Jarrett, L. (2017). Comparing sex buyers with men who do not buy sex new data on prostitution and trafficking. Journal of interpersonal violence, 32(23), 3601-3625.

Harrison, D. A., Kravitz, D. A., Mayer, D. M., Leslie, L. M., \& Lev-Arey, D. (2006). Understanding attitudes toward affirmative action programs in employment: Summary and meta-analysis of 35 years of research. Journal of Applied Psychology, 91(5), 1013.

Harvey, D. (2007). A brief history of neoliberalism: Oxford University Press, USA.

Hearn, J., Nordberg, M., Andersson, K., Balkmar, D., Gottzén, L., Klinth, R., Pringle, K., \& Sandberg, L. (2012). Hegemonic masculinity and beyond:40 years of research in sweden. Men and Masculinities, 15(1), 31-55.

Horswill, A., \& Weitzer, R. J. D. B. (2018). Becoming a client: The socialization of novice buyers of sexual services. Deviant Behavior, 39(2), 148-158.

Hosmer, D. W., Lemeshow, S., \& Sturdivant, R. X. (2013). Applied logistic regression (3rd ed.). Hoboken, NJ: John Wiley \& Sons, Inc.

Huysamen, M., \& Boonzaier, F. (2015). Men's constructions of masculinity and male sexuality through talk of buying sex. Culture, Health \& Sexuality, 17(5), 541-554.

Jewkes, R. K., Flood, M. G., \& Lang, J. (2015). From work with men and boys to changes of social norms and reduction of inequities in gender relations: A conceptual shift in prevention of violence against women and girls. The Lancet, 385(9977), 1580-1589.

Jones, A. (2015). Sex work in a digital era. Sociological Compass, 9(7), 558-570.

Jones, Z., \& Hannem, S. (2018). Escort clients' sexual scripts and constructions of intimacy in commodified sexual relationships. Symbolic Interaction, 41(4), 488-512.

Joseph, L. J., \& Black, P. (2012). Who's the man? Fragile masculinities, consumer masculinities, and the profiles of sex work clients. Men \& Masculinities, 15(5), 486506.

Kane, E. W., \& Whipkey, K. J. (2009). Predictors of public support for gender-related affirmative action: Interests, gender attitudes, and stratification beliefs. The Public Opinion Quarterly, 73(2), 233-254.

Knight, C. R., \& Brinton, M. C. (2017). One egalitarianism or several? Two decades of gender-role attitude change in europe. American Journal of Sociology, 122(5), 14851532.

Lahav-Raz, Y. (2019a). "Hunting on the streets": Masculine repertoires among israeli clients of street-based sex work. Sexuality \& culture.

Lahav-Raz, Y. (2019b). The prosumer economy and the sex industry: The creation of an online community of sex prosumers. Journal of Cultural Economy, 1-13.

Levtov, R. G., Barker, G., Contreras-Urbina, M., Heilman, B., \& Verma, R. (2014). Pathways to gender-equitable men:Findings from the international men and gender equality survey in eight countries. Men and Masculinities, 17(5), 467-501.

Milrod, C., \& Monto, M. A. (2012). The hobbyist and the girlfriend experience: Behaviors and preferences of male customers of internet sexual service providers. Deviant Behavior, 33(10), 792-810.

Milrod, C., \& Monto, M. A. (2016). Older male clients of female sex workers in the united states. Archives of Sexual Behavior, 1-10.

Milrod, C., \& Weitzer, R. (2012). The intimacy prism: Emotion management among the clients of escorts. Men \& Masculinities, 15(5), 447-467.

Minichiello, V., \& Scott, J. (2014). Male sex work and society: Columbia University Press.

Monto, M. A. (2010). Prostitutes' customers: Motives and misconceptions. In R. Weitzer (Ed.), Sex for sale: Prostitution, pornography and the sex industry (2nd ed., pp. 233254). New York: Routledge.

Monto, M. A., \& Hotaling, N. (2001). Predictors of rape myth acceptance among male clients 
of female street prostitutes. Violence Against Women, 7(3), 275.

Monto, M. A., \& Milrod, C. (2014). Ordinary or peculiar men? Comparing the customers of prostitutes with a nationally representative sample of men. International Journal of Offender Therapy and Comparative Criminology, 58(7), 802-820.

Monto, M. A., \& Milrod, C. (2019). Perceptions of provider power among sex buyers. Sexualities, online first, 1363460719831977.

Morgenroth, T., \& Ryan, M. K. (2018). Quotas and affirmative action: U nderstanding groupbased outcomes and attitudes. Social and Personality Psychology Compass, 12(3), e12374.

Nelson, A. J., Hausbeck Korgan, K., Izzo, A. M., \& Bessen, S. Y. (2019). Client desires and the price of seduction: Exploring the relationship between independent escorts' marketing and rates. The Journal of Sex Research, 1-17.

Peng, Y.-W. (2007). Buying sex: Domination and difference in the discourses of taiwanese piao-ke. Men \& Masculinities, 9(3), 315-336.

Pettinger, L. (2011). 'Knows how to please a man': Studying customers to understand service work. The Sociological Review, 59(2), 223-241.

Pettinger, L. (2013). Market moralities in the field of commercial sex. Journal of Cultural Economy, 6(2), 184-199.

Prasad, M. (1999). The morality of market exchange: Love, money, and contractual justice. Sociological Perspectives, 42(2), 181-214.

Sanders, T. (2008a). Male sexual scripts: Intimacy, sexuality and pleasure in the purchase of commercial sex. Sociology, 42(3), 400.

Sanders, T. (2008b). Paying for pleasure: Men who buy sex. Cullompton: Willan Publishers.

Scarborough, W. J., Sin, R., \& Risman, B. (2018). Attitudes and the stalled gender revolution: Egalitarianism, traditionalism, and ambivalence from 1977 through 2016. Gender \& Society, 0891243218809604.

Shumka, L., Strega, S., \& Hallgrimsdottir, H. K. (2017). "I wanted to feel like a man again": Hegemonic masculinity in relation to the purchase of street-level sex. Frontiers in Sociology, 2, 15.

Skilbrei, M.-L. (2012). The development of norwegian prostitution policies: A marriage of convenience between pragmatism and principles. Sexuality Research and Social Policy, 9(3), 244-257.

Smith, T. W., Marsden, P., Hout, M., \& Kim, J. (1976-2016). General social surveys, 19722016 [machine-readable data file]. Retrieved from: gssdataexplorer.norc.org

Stack, S., Adamczyk, A., \& Cao, L. (2010). Survivalism and public opinion on criminality: A cross-national analysis of prostitution. Social Forces, 88(4), 1703-1726.

Swets, J. A. (1988). Measuring the accuracy of diagnostic systems. Science(240), 1285-1293. Weitzer, R. (2009). Sociology of sex work. Annual Review of Sociology, 35, 213-234.

\section{Author Biographies}

Barbara G. Brents, $\mathrm{PhD}$, is a professor in the Department of Sociology at the University of Nevada, Las Vegas. Brents has been publishing research using the sex industry as a site to understand the intersections of gender, sexuality, culture and economics for the past 25 years. She is the co-author of Paying for Sex in the Digital Age (Routledge 2020) and The State of Sex: Tourism, Sex and Sin in the New American Heartland (Routledge 2010), a study of Nevada's brothels that situates the nation's only legal brothel industry in the political economy of contemporary tourism.

Takashi Yamashita, PhD, MPH, MA, is an associate professor of sociology and a faculty of the Gerontology PhD program at the University of Maryland, Baltimore County. His primary areas of research are social determinants of health and well-being, wider benefits of lifelong learning, and health literacy in the older population. 
Andrew L. Spivak, $\mathrm{PhD}$, is associate professor of Sociology at the University of Nevada, Las Vegas. He is the author of Sexual Violence: Beyond the Feminist-Evolutionary Debate (LFB, 2011) and co-author of Heartland Tobacco War (Lexington, 2013), as well as numerous articles, chapters, and reports related to topics including prison recidivism, special needs inmates, suicide and violent behavior, prostitution, juvenile justice processing, tobacco use and regulation, and residential segregation.

Olesya Venger, $\mathrm{PhD}$ is an assistant professor of Strategic Communication at the School of Journalism and Media Studies at the University of Nevada, Las Vegas. She conducts interdisciplinary research at the intersection of strategic communication and advertising planning, media sociology, regulations and media clearance, human trafficking and technology. Her work has been published in Journal of Advertising, Journal of Current Research and Issues in Advertising, Journal of Arab and Muslim Media Research, Journal of Virtual Worlds Research, Social Indicators Research and others.

Christina Parreira, MA, is a doctoral student in the Department of Sociology at the University of Nevada, Las Vegas. Parreira has been studying the sex industry for the past 6 years, exploring the intersections of gender, race, and social class in the legal Nevada brothels. She has also been involved in projects that examine clients of both legal and criminalized prostitution and underage prostitution on the streets of Las Vegas.

Alessandra Lanti is a doctoral student in the Department of Sociology at the University of Nevada, Las Vegas. She holds a Master of Arts in clinical psychology from UNLV and her current research combines scholarship in sociology, sexuality and psychology to help understand the relationship between stigma and sex workers' mental health as well as inform clinical treatment programs for stigmatized populations. Alessandra is also a licensed clinical professional counse- lor at Gender Justice Nevada specialized in providing support to individuals who work in the sex industry. She started and facilitates a no-cost weekly support and solidarity group for sex workers with a focus on stigma in Las Vegas, the only one of its kind. 
Table 1: Descriptive Statistics of the Study Participants by the Means to Access Illegal Sexual Services, and Comparisons to the National Average of Men Variables

$\begin{array}{cccc}\text { All participants } & \text { Media }^{2} & \text { In-person 2 } & \text { GSS 2014 } \\ (\mathrm{N}=519) & (\mathrm{n}=354) & (\mathrm{n}=165) & (\mathrm{n}=1,141)^{3} \\ \text { Mean (Standard } & \text { Mean (Standard } & \text { Mean (Standard } & \text { Weighted mean } \\ \text { Deviation) or } & \text { Deviation) or } & \text { Deviation) or } & \text { (Standard Error) } \\ \text { Percentage } & \text { Percentage } & \text { Percentage } & \text { or Percentage }{ }^{1}\end{array}$

\begin{tabular}{|c|c|c|c|c|}
\hline & Percentage & Percentage & Percentage & or Percentage $^{1}$ \\
\hline \multirow{4}{*}{ Non-Hispanic white (vs. all other race \& ethnicity) } & $47.84(12.26)$ & 47.35 (12.03) & $48.90(12.71)$ & $47.60(0.52)$ \\
\hline & {$[\mathrm{t}(518)=0.84]$} & {$[\mathrm{t}(353)=-0.05]$} & {$[\mathrm{t}(164)=1.51]$} & \\
\hline & $85.96 \% *$ & $88.17 \% *$ & 81.21\%* & $66.65 \%$ \\
\hline & {$\left[x^{2}(1)=87.25\right]$} & {$\left[x^{2}(1)=73.96\right]$} & {$\left[x^{2}(1)=15.74\right]$} & \\
\hline \multirow[t]{2}{*}{ Marital Status (married) } & $43.74 \% *$ & $46.05 \% *$ & $38.79 \% *$ & $55.04 \%$ \\
\hline & {$\left[x^{2}(1)=26.79\right]$} & {$\left[x^{2}(1)=11.57\right]$} & {$\left[x^{2}(1)=17.61\right]$} & \\
\hline \multirow[t]{2}{*}{ Education (college degree or higher) } & $34.17 \%$ & $34.84 \%$ & $32.73 \%$ & $30.81 \%$ \\
\hline & {$\left[x^{2}(1)=2.74\right]$} & {$\left[x^{2}(1)=2.70\right]$} & {$\left[x^{2}(1)=0.28\right]$} & \\
\hline Income (11 levels) $)^{5}$ & $5.71(3.25)$ & $5.98(3.30)$ & $5.12(3.07)$ & NA ${ }^{4}$ \\
\hline \multirow{2}{*}{$\begin{array}{r}\text { Agree with "A working mother can establish just as warm and secure a relationship with } \\
\text { her children as a mother who does not work." } \\
\text { (Positive attitude = agreed) }\end{array}$} & $88.25 \% *$ & $86.72 \% *$ & $91.52 \% *$ & $71.20 \%$ \\
\hline & {$\left[x^{2}(1)=73.55\right]$} & {$\left[x^{2}(1)=41.60\right]$} & {$\left[x^{2}(1)=33.21\right]$} & \\
\hline \multirow{3}{*}{$\begin{array}{r}\text { Disagree with "Most men are better suited emotionally for politics than are most } \\
\text { women" } \\
\text { (Positive attitude = disagreed) }\end{array}$} & $86.29 \% *$ & $88.10 \% *$ & $82.42 \% *$ & $79.95 \%$ \\
\hline & {$\left[x^{2}(1)=13.00\right]$} & {$\left[x^{2}(1)=14.63\right]$} & {$\left[x^{2}(1)=0.63\right]$} & \\
\hline & & & & \\
\hline \multirow{2}{*}{$\begin{array}{l}\text { Disagree with "It is much better for everyone involved if the man is the achiever outside } \\
\text { the home and the woman takes care of the home and family" } \\
\text { (Positive attitude = disagreed) }\end{array}$} & $86.41 \% *$ & $88.00 \% *$ & $83.03 \% *$ & $66.93 \%$ \\
\hline & {$\left[x^{2}(1)=88.27\right]$} & {$\left[x^{2}(1)=70.20\right]$} & {$\left[x^{2}(1)=19.32\right]$} & \\
\hline \multirow{2}{*}{$\begin{array}{r}\text { Agree with "Because of past discrimination, employers should make special efforts to hire } \\
\text { and promote qualified women." } \\
\text { (Positive attitude = agreed) }\end{array}$} & $48.06 \% *$ & $52.14 \% *$ & $39.39 \% *$ & $69.54 \%$ \\
\hline & {$\left[x^{2}(1)=112.38 .00\right]$} & {$\left[x^{2}(1)=50.19\right]$} & {$\left[x^{2}(1)=70.79\right]$} & \\
\hline
\end{tabular}

GSS = General Social Survey; ${ }^{*} p<0.05$ for the two-sample t-test [t (degrees of freedom)] or Pearson's Chi-square test [ $x^{2}$ (degrees of freedom)] (vs. GSS)

1. The weighted statistics (i.e., nationally representative figures) were estimated using the sampling weights provided in the GSS

2. The main means to access illegal sexual service (see the methods section for more detail)

3. Unweighted sample size

4. Not Applicable due to the incomparable response categories between the present survey and the GSS

5. 11 levels, roughly by $\$ 20,000$ [(1) Under $\$ 20,000,(2) \$ 20,000$ to $\$ 39,999 \ldots$ and $(11)$ over $\$ 200,000]$ 
Table 2: Estimated Coefficients from the Binary Logistic Regressions for the Means to Access to the Illegal Sexual Services

\begin{tabular}{|c|c|c|c|c|c|}
\hline Variables & Model 1 & Model 2 & Model 3 & Model 4 & Model 4b \\
\hline Dependent Variable & $\begin{array}{c}\text { Media vs. In- } \\
\text { person } \\
\text { Estimated } \\
\text { Coefficients (SE) }\end{array}$ & $\begin{array}{c}\text { Media vs. In- } \\
\text { person } \\
\text { Estimated } \\
\text { Coefficients (SE) }\end{array}$ & $\begin{array}{c}\text { Media vs. In- } \\
\text { person } \\
\text { Estimated } \\
\text { Coefficients (SE) }\end{array}$ & $\begin{array}{c}\text { Media vs. In- } \\
\text { person } \\
\text { Estimated } \\
\text { Coefficients (SE) }\end{array}$ & $\begin{array}{c}\text { Media vs. In- } \\
\text { person } \\
\text { Estimated } \\
\text { Coefficients (SE) }\end{array}$ \\
\hline
\end{tabular}

Independent Variables

Gender attitudes

A working mother can establish just as warm and secure a relationship with her children as a mother who does not work (Positive attitude)

$-0.50(0.32)$

Most men are better suited emotionally for politics than are most women (Positive attitude)

It is much better for everyone involved if the man is the achiever outside the home and the woman takes care of the home and family

(Positive attitude)

Because of past discrimination, employers should make special efforts to hire and promote qualified women

(Positive attitude)

Covariates

Age (years)

Non-Hispanic white (vs. all other race \& ethnicity)

$$
\text { Marital Status (married) }
$$

Education (college degree or higher) Household income

$0.46(0.26)$

$0.40(0.26)$

$0.52(0.19)^{*}$

$0.73(0.21)^{*}$

$-0.02(0.01)^{*}$

$0.79(0.29)^{*}$

$0.17(0.23)$

$0.01(0.22)$

$0.08(0.04)^{*}$

Model Quality Indicators

Akaike Information Criterion (AIC)

Area Under the Receiver Operating Characteristics Curve
650.43

0.52
649.33

0.53
647.69

0.53

643.75

604.50

0.64

$*_{\mathrm{p}}<0.05 ; \mathrm{SE}=$ Standard Error

The estimated coefficients show the log-odds of being in the media group (vs. the in-person group as a reference group)

See the methods section for the detailed classifications (media and in-person) 